\title{
Side Effects and Complications of Androgen Deprivation in Prostate Cancer Patients
}

\author{
Gustavo Fernandez-Castro ${ }^{1,2, *}$ \\ ${ }^{1}$ Sylvester Comprehensive Cancer Center, University of Miami, FL, USA \\ ${ }^{2}$ Division of Hematology-Oncology, University of Miami Hospital, FL, USA
}

\begin{abstract}
Androgen deprivation therapy has been used for years and its use has increased recently in the treatment of locally advanced and metastatic prostate cancer patients.

Frequent side effects of androgen deprivation therapy are hot flashes, neuropsychological, sexual dysfunction, anemia and physical and metabolic changes. The most concerning ones are an increase risk of diabetes, cardiovascular disease, fractures and in some cases a possibly increase in mortality.

Since not every patient with prostate cancer will die due to their disease the benefit and risk of androgen deprivation therapy should be discussed.

We encourage in these patients to have routine surveillance and control of their glucose, modification of cardiac risk factors and to have preventive measures and treatment of osteoporosis.
\end{abstract}

\section{INTRODUCTION}

Of those who died, fifty-four percent of prostate cancer patients, died of prostate carcinoma and forty-six percent died from other conditions. The causes of death after prostate carcinoma were cardiovascular conditions, other cancers, respiratory conditions and others. Age was found to be associated with cause of death; in which more than $75 \%$ of the deceased patients diagnosed with prostate cancer before age of 60 years died of the disease. However only $40 \%$ of decedents diagnosed after age of 80 died of the disease [1]. In a more recent population based cohort study of 180,973 patients with prostate cancer, most deaths including those with non-localized disease, are due to non prostate causes. By 1995-1996 the proportion of prostate cancer death was similar to that due to cardiovascular disorder (around 27\%) and much less than all other causes combined (around 46\%) [2].

Since not every prostate cancer patient will die due to prostate cancer, the decision to start treatment such as radiation, surgery or androgen-deprivation treatment (ADT) depends on a delicate balance of risk-benefit ratio. Bilateral Orchiectomy or medical castration with luteinizing hormone -releasing (LHRH) agonist are the recommended initial androgen deprivation therapy (ADT) for metastatic prostate cancer. On the basis of information supporting a small survival advantage, combined androgen blockade (CAB) (castration combined with an antiandrogen) should also be

*Address correspondence to this author at the Sylvester Comprehensive Cancer Center, University of Miami, FL, USA and Division of HematologyOncology, University of Miami Hospital, FL, USA; Tel: 305243 4909; Fax: 305243 6772; E-mail: GFernandez3@med.miami.edu considered [3]. LHRH is also used in combination with radiation therapy in locally advanced disease and as adjuvant therapy in patients with positive lymph nodes after radical prostatectomy. In the last 2 decades, during the PSA era, the use of ADT has dramatically increased. Widespread early detection and aggressive treatment for prostate cancer in the USA has been associated with more ADT use among men over time [4]. Although ADT was commonly used in men with documented metastatic prostate cancer before the PSA era, men are now being treated with ADT for earlier stage disease. ADT treatment has side effects related to the decrease of testosterone; some of these can be serious or can reduce quality of life. Hence, the importance of an understanding, preventing, recognizing and treating these side effects, as well as having a thorough discussion about pro and cons of treatment with the patient, are needed.

\section{SIDE EFFECTS OF ADT}

These include hot flashes, anemia, sexual dysfunction, neuropsychological including effects on cognition and mood, metabolic effects including hyperglycemia and insulin resistance as well as dyslipidemia and metabolic syndrome. Other effects include cardiovascular, musculoskeletal effects such as osteoporosis, fractures and muscle wasting. Other physical effects include gynecomastia, weight gain with an increase in fat mass, sarcopenia and loss of lean body mass.

\section{Hot Flashes}

A hot flash is a subjective sensation of warmth of the upper body that lasts from 30 seconds to 5 minutes. It is more frequent at night, and can be preceded by palpitations or headaches. It can be associated with weakness, faintness 
or vertigo and usually ends in profuse sweating and a cold sensation [5].

The etiology of hot flashes is not clear, although it is possibly associated with inappropriate stimulation of the hypothalamic thermoregulatory center resulting in peripheral vasodilatation $[6,7]$.

Hot flashes occur within several months after orchiectomy or medical castration. For unknown reasons, the incidence is higher after medical castration and is approximately $70 \%$.

It does not represent a serious adverse effect; however it can be very unpleasant and affect quality of life. Megestrol acetate, Cyproterone acetate, clonidine, antidepressants, gabapentin and acupuncture have been used with different results.

\section{Anemia}

Androgens stimulate erythropoiesis, so a decrease in testosterone can produce anemia, however pathophysiology of the anemia remains unclear [8]. This is a normocytic and normochromic anemia and can affect quality of life due to fatigue. It usually resolves after ADT is discontinued. Strum et al., described the extent of the anemia occurring in prostate cancer patients receiving combined hormone blockade. In that study hemoglobin levels declined significantly in all patients from a mean baseline of $14.9 \mathrm{~g} / \mathrm{dL}$ to mean 13.1 $\mathrm{g} / \mathrm{dL}$ at 3 months. Hemoglobin levels continued to decline during treatment to a mean nadir of $12.3 \mathrm{~g} / \mathrm{dL}$ at a mean of 5.6 months of $\mathrm{CAB}$, representing a mean absolute hemoglobin decline at nadir of $2.54 \mathrm{~g} / \mathrm{dL}$. In $90 \%$ of the patients, the relative decline in hemoglobin was more than $10 \%$ and in $13 \%$ of patients it was more than $25 \%$ [9] (Table 1).

In other studies, levels of hemoglobin decreased more than $25 \%$ in $15 \%$ of patients and there was not significant difference in low levels of hemoglobin among the patient with different pathologic grading and clinical staging [10] (Table 1).

It is important that every patient with anemia should be worked up before starting ADT and correctable causes should be treated. Patients on ADT who are symptomatic due to the anemia, or with severe coronary artery disease may require blood transfusion or may need to have treatment stopped. Erythropoietin-Stimulating agents are not approved by the FDA for treatment in this setting unless patient is re- ceiving concomitant chemotherapy. Anemia improves slowly after cessation of treatment.

\section{Sexual Dysfunction}

Erectile function (ED) is a complex neurovascular phenomena modulated by several biochemical and physiological factors. Testosterone is necessary for normal sexual desire, spontaneous erections and ejaculation. There is an abundance of animal evidence of the role of androgens in cellular, molecular and physiological mechanism associated with erection. A significant decrease in testosterone levels is observed in the aging process [11]. Also abdominal obesity is associated with reduced testosterone level [12].

Patients under ADT commonly have the same vascular risk factors of coronary artery disease that can cause erectile dysfunction [13]. There is a high prevalence of erectile dysfunction among men with diabetes and hypertension. Among men with diabetes, the crude prevalence of erectile dysfunction is near 50\% [14]. So many older men have sexual dysfunction at baseline prior to ADT initiation. Also in this population previous radical prostatectomy or radiation therapy can compromise sexual function even more.

ADT affects both libido and erectile function. The vast majority of men receiving continuous ADT who are potent prior to treatment develop sexual dysfunction. Loss of libido in men receiving $\mathrm{GnRH}$ agonists usually develops within the first several months, and erectile dysfunction follows. Not all men on ADT have loss of libido, suggesting other factors may impact severity such as testosterone level and or age.

In 395 prostate cancer patients on ADT (mean age of 71.7 years) and at mean follow-up of 87 months, 57 (14.4\%) patients reported ED; 40 of these $(70 \%)$ reported new-onset ED, while 17 (30\%) reported ED before ADT. On multivariate analysis, age $<70$ years $(\mathrm{P}<0.001)$ and the absence of $\mathrm{DM}(\mathrm{P}=0.024)$ were associated with reporting $\mathrm{ED}$ after ADT [15].

Education and counseling interventions can improve sexual function. There are pharmacological and non pharmacological interventions for erectile dysfunction. Non pharmacological interventions include, penile prostheses, intracavernosal injections and vacuum constriction devices. Oral drugs, such as the phosphodiesterase inhibitors, vardenafil, sildenafil and tadalafil are used as a first line. All increase intracavernosal cyclic GMP levels, and each one has been

Table 1. Anemia

\begin{tabular}{|c|c|c|c|}
\hline Author & Prostate CA Patients & Treatment & Findings Hem g/dl \\
\hline Strum [9] & $\begin{array}{l}\text { 133p (93 early stage) } \\
\text { (40个 Psa or Mets) }\end{array}$ & $\begin{array}{l}\text {-Orchiectomy } \\
-121 / 133(91 \%) \\
\text { Leuprolide Acetate(7..5mg IM monthly) } \\
-116 / 133(87 \%) \\
\text { Flutamide } 250 \mathrm{mg} \text { PO q8h }\end{array}$ & $\begin{array}{l}\text { Baseline / } 3 \mathrm{M} / 6 \mathrm{M} \\
14,9 / 13.1 / 12.3 \\
90 \% \text { p. .Hem } \downarrow \geq 10 \% \\
13 \% \text { p Hem } \downarrow \geq 25 \%\end{array}$ \\
\hline Qian [10] & $\begin{array}{l}136 \text { p (76p T1-T3/NoM0) } \\
\text { (70p T1-T4/N+/M0-1) }\end{array}$ & -Orchiectomy and Flutamide 250mg Po TID & $\begin{array}{l}\text { Baseline } / 6 \mathrm{M} \\
13.6 / 11.3 \\
90 \% \text { p. .Hem } \downarrow \geq 10 \% \\
15 \% \text { p Hem } \downarrow \geq 25 \%\end{array}$ \\
\hline
\end{tabular}


proven to be effective in restoring erectile function, allowing for satisfactory sexual intercourse. These medications are contraindicated in patient taking nitrates or with severe coronary artery disease. Patients receiving ADT on study, showed response rates of $33-80 \%$ to medical therapy, including $44 \%$ response rate in those receiving phosphodiesterase-5 inhibitor monotherapy [15].

Monotherapy with antiandrogens is an alternative form of hormone therapy that is associated with less sexual dysfunction; however they do not represent a form of medical castration, since they elevate rather than lower serum testosterone levels. These agents are not approved as monotherapy to treat prostate cancer in the United States. Intermittent ADT may allow for recovery of sexual function during offtreatment intervals.

\section{Neuropsychological and Cognition}

Small uncontrolled studies may support the ADT effect on cognition. However, prostate cancer patients can present with underlying cognitive issues.

In a study that included 26 elderly men (mean age 65 years) with newly diagnosed prostate cancer, cognitive testing was done at baseline and at 6 and 12 months on androgen deprivation therapy. At 6 months all patients have castrate levels of testosterone. Cognitive performances were evaluated using verbal and memory tests, as well as tests of processing speed and attention. Significant associations between cognitive performances and testosterone decline were documented such as visuomotor slowing, slowed reaction times in some attention domains including working memory, an impaired hit rate in a vigilance test, and an impaired delayed recall and recognition speed of letters, but with an improvement in object recall [16] (Table 2).
Jenkins et al., assessed in a prospective study, whether temporary 3-5 month treatment with a luteinizing-hormone releasing hormone (LHRH) agonist before radical radiotherapy had a short- or long-term affect on cognitive function. Thirty-two patients with localized prostate cancer had cognitive assessments at baseline before the start of ADT, at 3 months or on completing drug treatment but before radiotherapy, and at 9 months. Eighteen men with no prostate cancer (controls subjects) completed the cognitive tests at the same times. There was a significant cognitive decline (on at least one cognitive task) at 3 months in 15 $(47 \%)$ patients vs three $(17 \%)$ of controls (odds ratio 4.412 , $\mathrm{P}=0.033$ ). Most patients (nine of 15) who had a change in performance declined on tasks of spatial memory and ability [17] (Table 2).

In Green's study eighty-two men with extraprostatic prostate cancer were randomly assigned to receive either continuous LHRH analogs, cyproterone acetate (a steroidal antiandrogen) or close clinical monitoring. These patients underwent cognitive assessments at baseline and before starting treatment and then 6 months later. Compared with the baseline assessments, men receiving androgen suppression monotherapy performed worse in two of 12 tests of attention and memory; 24 of 50 men randomized to active treatment and assessed 6 months later had a clinically significant decline in one or more cognitive tests but not one patient randomized to close monitoring showed a decline in any test performance. In his study he concludes that pharmacological androgen suppression monotherapy for prostate cancer may be associated with impaired memory, attention and executive functions [18] (Table 2).

Clinical significance of these findings remains unclear and there are no definitive recommendations on how to treat or prevent cognitive impairment [19].

Table 2. Cognition and Mood

\begin{tabular}{|c|c|c|c|}
\hline Author & Prostate CA Patients & Treatment & Findings \\
\hline Salminen [16] & $\begin{array}{l}\text { 26p. Newly diagnosed } \\
\text { No Mets }\end{array}$ & $\begin{array}{l}\text {-Radiation Therapy } \\
\text {-Flutamide 250mg PO q8h x } 4 \text { weeks } \\
\text {-Leuprolide (11.25mg sq q3 x 12M) }\end{array}$ & $\begin{array}{l}\text { Slowing in some cognitive domains } \\
\text { Impaired hit rate in the vigilance test }\end{array}$ \\
\hline Jenkins [17]. & $\begin{array}{l}\text { 32p. Early Stage Prostate Ca. } \\
\text { 18p. Control group }\end{array}$ & $\begin{array}{l}\text { - Cyproterone acetatate x } 3 \text { weeks(CPA) } \\
\text { - Followed by Goserelin monthly } \\
\text { 3-5months } \\
\text { - Followed by Radiation Therapy }\end{array}$ & $\begin{array}{l}\text { Cognitive decline } \\
47 \% \text { vs. } 17 \% \text { at } 3 \text { months } \\
\text { (P } 0.033 \text { ) }\end{array}$ \\
\hline Green [18]. & $\begin{array}{l}\text { 82p. Extraprostatic Prost. CA. } \\
\text { (palliative treatment) }\end{array}$ & $\begin{array}{l}\text { 39p. Continuous LHRH (Leuprorelin 19) } \\
\text { (Goserelin 20) } \\
11 \mathrm{p} . \text { CPA } \\
\text { 15. Monitoring }\end{array}$ & $\begin{array}{l}24 \text { of } 50 \text { men on active treatment assessed at } \\
6 \text { months had a significant declined in one ore } \\
\text { more cognitive test } \\
0 \text { patient randomize to monitoring had a } \\
\text { cognitive decline }\end{array}$ \\
\hline $\operatorname{Pirl}[21]$ & $\begin{array}{l}\text { 52p. Locally advanced or } \\
\text { Lymph node positive or } \\
\text { Recurrent prostate CA } \\
\text { No bone mets }\end{array}$ & $\begin{array}{l}\text { Randomize to: } \\
\text { - leuprolide } 22.5 \mathrm{mgIM} \mathrm{q} 3 \mathrm{~m} \times 12 \mathrm{~m} \\
\text { (+ bicalutamide } 50 \mathrm{mg} \text { PO qd x } 4 \text { weeks) } \\
\text { - bicalutamide } 150 \mathrm{mg} \text { po qd x } 12 \mathrm{~m}\end{array}$ & $\begin{array}{l}\text { Mild depression } 10 \text { to } 16 \% \\
\text { (n/s different) } \\
\text { Hormone therapy does not appear to cause } \\
\text { significant changes in depression }\end{array}$ \\
\hline
\end{tabular}




\section{Neuropsychological Issues and Mood}

Data suggests a significant rate of major depression in men with prostate cancer receiving ADT and that men with past histories of depression may be at particular risk for recurrence of their depression while undergoing this treatment.

Pirl et al. studied the prevalence rates and risk factors associated with major depression in men with prostate cancer receiving ADT. 45 patients were surveyed for depression with the SCID for Axis I disorders for DSM-IV and the Beck Depression Inventory. They found that a major depressive disorder was prevalent in $12.8 \%$ of the men with prostate cancer receiving ADT, eight times the national rate of depression in men, 32 times the rate in men over 65 years old. Past history of depression was significantly associated with current depression in this population [20] (Table 2).

One of the first prospective studies examined the development of depressive symptoms and fatigue among men with locally advanced prostate cancer receiving hormone therapy. Fifty-two men with advanced or recurrent prostate cancer were randomly assigned to receive either parenteral leuprolide or oral bicalutamide. Patients completed the Beck Depression Inventory (BDI) and Fatigue Severity Scale (FSS) at pretreatment baseline, 6 months, and 12 months. The Rates of at least mild depression ranged from 10.4 to $16.3 \%$ over the 12 months and were not significantly different at each time point. There were no significant differences in depression between the two types of hormone therapy. In this study, hormone therapy did not appear to cause clinically significant changes in depression among men with locally advanced prostate cancer. However, fatigue increased significantly over the study period. These conclusions were limited due to the lack of control group and the small sample size [21] (Table 2).

There has been little study on the effects of interventions on mood in prostate cancer patient on ADT.

Antidepressant and cognitive behavioral treatment may be used. More research is needed and larger studies are required in this field.

\section{Metabolic}

ADT is associated with several metabolic disorders such as increase incidence of Hyperglycemia, insulin resistance, metabolic syndrome and dyslipidemia.

Short-term treatment with leuprolide and bicalutamide significantly decreased insulin sensitivity in men with prostate cancer. In a prospective 12-wk study, Smith et al. assessed the effects of short-term GnRH agonist treatment on insulin sensitivity. 25 men with locally advanced or recurrent prostate cancer and no radiographic evidence of metastases, no history of diabetes mellitus, and no evidence of diabetes mellitus at baseline visit, were treated with Leuprolide depot and bicalutamide. Oral glucose tolerance tests were performed at baseline and wk 12. Insulin sensitivity index decreased by $12.9 \%(P=0.02)$. Insulin sensitivity by homeostatic model assessment decreased by $12.8(\mathrm{P}=0.02)$. Fasting plasma insulin levels increased by $25.9 \%(\mathrm{P}=0.04)$. Mean glycosylated hemoglobin also increased significantly ( $\mathrm{P}<0.001)$. One patient developed diabetes during the 12 wk study [22] (Table 3).
Basaria et al. evaluated the effects of long-term ADT on fasting glucose levels, insulin levels, and insulin resistance. In this study 53 men were evaluated. They had three groups of patients, including 18 men with prostate cancer who received ADT for at least 12 months prior to the onset of the study (the ADT group), 17 age-matched men with nonmetastatic prostate cancer who had undergone prostatectomy and/or received radiotherapy and who were not receiving ADT (the non-ADT group), and 18 age-matched controls (the control group). None of the men had a known previous history of diabetes mellitus. Serum total testosterone levels and free testosterone levels were significantly lower in the ADT group compared with the other groups as expected. Men in the ADT group had significantly higher fasting levels of glucose and insulin levels. Glucose levels were $131 \mathrm{mg} / \mathrm{dL}$ in the ADT group compared with $103 \mathrm{mg} / \mathrm{dL}$ in the nonADT group $(\mathrm{P}=0.01)$ and $99 \mathrm{mg} / \mathrm{dL}$ in the control group $(\mathrm{P}<0.01)$. Insulin levels were $45.0 \mathrm{uU} / \mathrm{mL}$ in the ADT group compared with $24.0 \mathrm{uU} / \mathrm{mL}$ in the non-ADT group $(\mathrm{P}=0.05)$ and $19.0 \mathrm{uU} / \mathrm{mL}$ in the control group $(\mathrm{P}=0.02)$. Men in the ADT group also were more insulin resistant [23] (Table 3).

Derweesh, investigated in a retrospectively analysis the incidence of new-onset diabetes mellitus (NODM) and the worsening glucose control in established DM after starting androgen-deprivation therapy (ADT) for prostate cancer. Patients received ADT between January 1989 and July 2005. 396 patients (median age 73.2 years; median BMI of 26.7 $\mathrm{kg} / \mathrm{m}(2)$ were analyzed. At a median follow-up of 60 months, $36(11.3 \%)$ patients developed NODM. In 77 patients with pre-existing DM, there was an increase of $>/=10 \%$ in serum HbA1c or fasting glucose levels in 15 $(19.5 \%)$ and 22 (28.6\%), respectively. On multivariate analysis, a BMI of $>/=30 \mathrm{~kg} / \mathrm{m}(2)$ was associated with an increased risk of developing NODM (odds ratio 4.65, P = 0.031) [24] (Table 3).

Patients on ADT have an increased incidence of metabolic syndrome. The metabolic syndrome represents a constellation of lipid and non lipid risk factors of metabolic origin. This syndrome is closely linked to a generalized metabolic disorder called insulin resistance in which the normal actions of insulin are impaired.

According to the Adult treatment panel III criteria, metabolic syndrome is present if three on the following five criteria are met: fasting plasma glucose level more than $110 \mathrm{mg} / \mathrm{dl}$, serum triglyceride level $\geq 150 \mathrm{mg} / \mathrm{dl}$, serum high density lipoprotein (HDL) level less than 40mg/dl, waist circumference more than $102 \mathrm{~cm}$ and blood pressure of $\geq$ $130 / 85 \mathrm{~mm} / \mathrm{Hg}$ [25].

Basaria in a cross sectional study evaluated the prevalence of metabolic syndrome in men undergoing long-term ADT [26] (Table 3). Metabolic syndrome was present in more than $50 \%$ of the men undergoing long-term ADT. Abdominal obesity and hyperglycemia were responsible for this higher prevalence. In this study 58 men, including 20 with prostate cancer undergoing ADT for at least 12 months (ADT group), 18 age-matched men with non metastatic prostate cancer who had received local treatment and were recently found to have an increasing prostate-specific antigen (non-ADT group), and 20 age-matched controls (control 
Table 3. Metabolic Effects

\begin{tabular}{|c|c|c|c|}
\hline Author & Prostate CA Patients & Treatment & Findings \\
\hline Smith [22] & $\begin{array}{l}25 \mathrm{p} . \text { Locally advanced or recurrent } \\
\text { prostate cancer. No mets. No } \\
\text { previous history of diabetes. } \\
\text { Subject evaluated after } 12 \mathrm{w} \text { of } \\
\text { treatment. }\end{array}$ & $\begin{array}{l}\text {-Bicalutamide } 50 \mathrm{mg} \text { PO qd x } 4 \text { weeks } \\
\text {-Lupron depot } 22.5 \mathrm{mg} \text { IMq } 3 \mathrm{M} \text {. }\end{array}$ & $\begin{array}{l}\text {-Mean \%fat body mass } \uparrow 4.3 \% \\
\text {-Insulin sensitivity index } \downarrow 13 \% \\
\text {-Fasting plasma Insuilin } \uparrow 26 \% \\
\text {-Mean glycosylated hemoglobin } \\
\text { levels } \uparrow \text { from } 5.46 \text { to } 5.62 \text { (p0.001) } \\
\text {-ADT increase triglycerides and HDL cholesterol }\end{array}$ \\
\hline Basaria [23-26] & $\begin{array}{l}\text { 58p. } 3 \text { groups } \\
\text {-20p Recurrent Prost CA or } \\
\text { Met on ADT x } 12 \mathrm{~m} \text { prior } \\
-18 \mathrm{p} \text {. NonMet Prost Ca. } \\
\text { (s/p Prostatectomy or XRT) } \\
\text { No ADT. Eugonadal } \\
-20 \text { age matches eugonadal } \\
\text { men with normal PSA }\end{array}$ & $\begin{array}{l}\text {-Average duration of ADT } \\
45 \mathrm{~m}(12 \text { to } 101) . \\
3 \mathrm{p} \text { Orchiectomy } \\
\text { 17p .GnRH agonist }\end{array}$ & $\begin{array}{l}\text {-Men in ADT group had significant } \uparrow \text { levels of } \\
\text { glucose and insulin and were more insulin resistant } \\
\text { ADT vs Non ADT group } \\
\text {-Fasting glucose: } \mathrm{mg} / \mathrm{dl} \\
\text { Mean } 138 \text { vs } 100 \text { p } 0.002 \\
\text {-BMI } \\
\text { Mean } 29.6 \text { vs } 27.6 \text { p } 0.001 \\
\text {-Triglycerides } \\
55 \% \text { vs } 44 \% \text { (P } 0.02 \text { ) } \\
\text {--------------------------------- } \\
\text { Metabolic syndrome was present in more than } 50 \% \\
\text { of met on ADT }\end{array}$ \\
\hline Derweesh [24] & $\begin{array}{l}396 p . T 1-T 3-249 p \\
\text { N+ - } 8 p \\
\text { M1 }-14 p \\
?-125 p \\
\text { No neoadjuvant hormones }\end{array}$ & $\begin{array}{l}\text { ADT. Medical 371p } \\
\text { Orchiectomy 25p } \\
\text { XRT 199p } \\
\text { RP 32p }\end{array}$ & $\begin{array}{l}\text { Median follow up: } 60 \mathrm{M} \\
-11 \% \text { p developed New onset } \\
\text { Diabetes } \\
\text {-In } 77 \mathrm{p} \text { with preexisting diabetes } \\
\text { there was an } \uparrow \text { of } \geq 10 \% \text { in HbA1c. } \\
\text {-BMI of } \geq 30 \mathrm{~kg} / \mathrm{m} 2 \text { associated with } \\
\text { increased risk of Diabetes }\end{array}$ \\
\hline Smith [27] & $\begin{array}{l}\text { 40p. Locally Advanced Prostate } \\
\text { Cancer, Node + or } \uparrow \text { PSA. No mets }\end{array}$ & LHRH q $3 \mathrm{~m} \times 48$ weeks & $\begin{array}{l}\text { Total Cholesterol } \uparrow 9 \% \\
\text { HDL Cholesterol } \uparrow 11 \% \\
\text { LDL Cholesterol } \uparrow 7 \% \\
\text { Serum Triglycerides } \uparrow 26 \% *\end{array}$ \\
\hline
\end{tabular}

$*$ all $\mathrm{p}<0.05$.

group). Men on ADT had significantly higher body mass index and lower total and free testosterone levels. Men in the non-ADT and control groups were eugonadal. Metabolic syndrome was defined according to the Adult Treatment Panel III criteria. The prevalence of metabolic syndrome was higher in the ADT group compared with the non-ADT $(\mathrm{P}<.01)$ and control $(\mathrm{P}=.03)$ groups. Among the components of metabolic syndrome, men on ADT had a higher prevalence of abdominal obesity and hyperglycemia. Androgen-deprived men also had elevated triglycerides compared with controls $(\mathrm{P}=.02)$. The prevalence of hypertension and low high-density lipoprotein levels were similar.

ADT cause several changes in serum lipids. In a study with forty men with locally advanced, node-positive or biochemical recurrent prostate cancer, no radiographic evidence of metastases, and no prior androgen deprivation therapy were treated with LHRH every $12 \mathrm{wk}$ for $48 \mathrm{wk}$. Serum total cholesterol, HDL cholesterol, and LDL cholesterol concentrations increased by $9.0 \%$ plus or minus $2.1 \%(P<0.001)$, $11.3 \%$ plus or minus $2.6 \%(P<0.001)$, and $7.3 \%$ plus or minus $3.5 \%(P=0.05)$ respectively. Serum triglycerides increased by $26.5 \%$ plus or minus $10.0 \%(P=0.01)$ [27] (Table 3). Also short term ADT significantly increased serum triglycerides levels and HDL cholesterol [22]. The observed increased in HDL cholesterol levels contrasts to the low levels of HDL cholesterol associated with the classic metabolic syndrome. This increase HDL is difficult to quantify in the overall cardiovascular risk.

The NCEP-ATP III provides guidelines for the evaluation and treatment of high cholesterol in the general population [28].

\section{Cardiovascular}

These metabolic abnormalities can confer a high cardiovascular risk for morbidity and mortality. Some analysis have suggested an association between ADT and increase risk if cardiovascular disease (Table 4).

Keating et al. did an observational study of a populationbased cohort of 73,196 fee-for-service Medicare enrollees age 66 years or older who were diagnosed with loco- regional prostate cancer during 1992 to 1999 and observed through 2001 [29]. Men with metastatic disease were excluded. They used a Cox proportional hazards models to assess whether treatment with GnRH agonists or orchiectomy was associated with diabetes, coronary heart disease, 
Table 4. Cardiovascular Effects

\begin{tabular}{|c|c|c|c|}
\hline Author & Prostate CA Patients & Treatment & Findings \\
\hline Keating [29] & $\begin{array}{l}73,196 \mathrm{p} \\
\text { Loco-Regional. } \\
\text { No mets }\end{array}$ & $\begin{array}{l}\text {-Orchiectomy }(6.9 \%) \text { or } \\
\text {-GnRH agonist }(36.3 \%)\end{array}$ & $\begin{array}{l}\text { GnRH agonist } \uparrow \text { Risk } \\
\text {-Diabetes (HR 1.44) } \\
\text {-Coronary heart disease (HR 1.16) } \\
\text {-Myocardial Infarction (HR 1.11) } \\
\text {-Sudden Cardiac Death(HE 1.16) }\end{array}$ \\
\hline Tsai [30] & $\begin{array}{l}4892 \mathrm{p} \\
\text { Localized prostate cancer }\end{array}$ & $\begin{array}{l}3263 \mathrm{p} . \mathrm{S} / \mathrm{p} \text { Radical Prostatectomy } \\
1630 \mathrm{p} . \mathrm{S} / \mathrm{p} \text { Radiation Therapy } \\
-1015 \mathrm{p} \text { treated with ADT } \\
\text {-Average duration of ADT } 4.1 \mathrm{~m}\end{array}$ & $\begin{array}{l}\text { Among } 65 \text { y old and s/p Prostatectomy. } \\
-5.5 \% \text { cardiovascular death in ADT patient vs. } 2 \% \text { in } \\
\text { those with no ADT }(\mathrm{p}=0.002)\end{array}$ \\
\hline Saigal [31] & $\begin{array}{l}22816 \mathrm{p} \\
\text { All stages }\end{array}$ & $\begin{array}{l}\text { 4810p on ADT. } \\
\text { Median time on ADT } 36 \mathrm{~m}\end{array}$ & $\begin{array}{l}\text { Patients on ADT have more cardiovascular events } 12 \text { to } \\
60 \mathrm{~m} \text { after diagnosis ( } 24 \% \text { vs } 18 \% \text { ) }\end{array}$ \\
\hline Hayes [32] & $12792 p$ & $\begin{array}{l}\text { S/p Brachitherapy } \pm \text { radiation therapy } \\
\text { Median use of ADT } 4 \text { months }\end{array}$ & $\begin{array}{l}\text { In patient with ADT use and history of Myocardial } \\
\text { Infarction and or Stroke } 17 \% \text { died comparing with } 12 \% \\
\text { with no MI or stroke history. }\end{array}$ \\
\hline
\end{tabular}

myocardial infarction, and sudden cardiac death. In the study more than one third of men received a GnRH agonist during follow-up. GnRH agonist use was associated with increased risk of incident diabetes (adjusted hazard ratio [HR], 1.44; P $<.001$ ), coronary heart disease (adjusted HR, 1.16; P < .001 ), myocardial infarction (adjusted HR, 1.11; $\mathrm{P}=.03$ ), and sudden cardiac death (adjusted HR, 1.16; P = .004). Men treated with orchiectomy were more likely to develop diabetes (adjusted HR, 1.34; $\mathrm{P}<.001$ ) but not coronary heart disease, myocardial infarction, or sudden cardiac death (all $\mathrm{P}>$ .20). In adjusted analysis an increased risk of diabetes and coronary heart disease was evident among men on GnRh agonist for as few a 1 to 4 months. Risk remained elevated among men who continued on treatment longer.

From the Cancer of the Prostate Strategic Urologic Research Endeavor (CAPSURE) database, data on 3262 patients treated with radical prostatectomy and 1630 patients treated with external beam radiation therapy, brachytherapy, or cryotherapy for localized prostate cancer were obtained [30]. They investigated whether ADT use is associated with an increased risk of death from cardiovascular causes in patients treated for localized prostate cancer. The median follow-up time was 3.8 years. Among the 1015 patients who received ADT, the median duration of ADT use was 4.1 months. In a competing risks regression analysis that controlled for age and risk factors for cardiovascular disease, both ADT use (adjusted hazard ratio $[\mathrm{HR}]=2.6 ; \mathrm{P}=.002$ ) and age (adjusted HR $=1.07 ; \mathrm{P}=.003$ ) were associated with statistically significantly increased risks of death from cardiovascular causes in patients treated with radical prostatectomy. Among patients 65 years or older treated with radical prostatectomy, the 5-year cumulative incidence of cardiovascular death was $5.5 \%$ in those who received ADT and $2.0 \%$ in those who did not $(\mathrm{P}=0.002)$. Among patients 65 years or older treated with external beam radiation therapy, brachytherapy, or cryotherapy, ADT use was associated with a higher cumulative incidence of death from cardiovascular causes, but the difference did not reach statistical significance.

In another retrospective study, the authors attempted to measure the risk for subsequent cardiovascular morbidity in men with prostate cancer who received ADT [31]. A total of 22,816 prostate cancer men who were diagnosed between 1992 and 1996 were identified.

The authors calculated the risk of subsequent cardiovascular morbidity in men with prostate cancer who were treated with ADT. Newly diagnosed prostate cancer patients who received ADT for at least 1 year were found to have a $20 \%$ higher risk of serious cardiovascular morbidity compared with similar men who did not receive ADT. Patients began incurring this higher risk within 12 months of treatment.

Recently, Hayes et al. did a retrospective review with 12,792 men with favorable-risk prostate cancer patient (PSA $<20 \mathrm{ng} / \mathrm{ml}$, Gleason $<=7$, clinical stage $<=\mathrm{T} 2 \mathrm{c}$ ), treated between 1991 and 2007 with Brachytherapy +/- EBRT with or without neoadjuvant ADT. Median AST use was 4 months. In patient with ADT use and history of Myocardial Infarction and or Stroke $17 \%$ died comparing with $12 \%$ with no MI or stroke history. The difference was statistically significant [32].

These studies are retrospective analyses, and cardiovascular morbidity and mortality should be an endpoint in prospective studies of prostate cancer patient on ADT.

\section{Musculoskeletal}

The most important risk factors for low bone mineral density (BMD) mediated osteoporotic fracture in men without a known diagnosis of osteoporosis or fracture are increase age (> 70years) and low body weight (body mass in- 
dex $<20$ to $25 \mathrm{~kg} / \mathrm{m} 2$ ). Other risk factors include weight loss, physical inactivity, corticosteroid use, previous osteoporotic fracture and androgen deprivation therapy [33].

Mittan et al. demonstrated a significant loss of bone in men with prostate cancer after receiving GnRH [34]. In his study BMD and serum and urine concentrations of markers of bone turnover were determined in men with prostate cancer and in age-matched controls. Measurements were taken before GnRH therapy and 6 and 12 months after instituting therapy. After 12 months of GnRH therapy, the BMD of the total hip and ultra distal radius decreased significantly $(\mathrm{P}<$ $0.001)$ in men with prostate cancer compared with the controls. The mean bone loss was $3.3 \%$ and $5.3 \%$, respectively. The observed reduction in BMD in the spine $(2.8 \%)$ and the femoral neck $(2.3 \%)$ did not reach statistical significance. Of importance no significant bone loss was observed in the control subjects. The concentration of the urine marker of bone resorption, N-telopeptide, was significantly increased from baseline and from controls at both 6 and 12 months in patients treated with GnRH analog therapy compared with control subjects $(\mathrm{P}<0.05)$.

Thus, the decreased total hip and ultra distal radius BMD and increased urinary N-telopeptide concentration after testosterone withdrawal demonstrate an increase in trabecular bone loss and enhanced bone resorption (Table $\mathbf{5}$ ).

A nationwide, population-based epidemiological case control study was done in Denmark [35]. This study covered 15,716 men aged $>50$ years presenting with a fracture at any hospital in 2000, and 47,149 age-matched control men. A previous diagnosis of prostate cancer had been recorded in $1.3 \%$ of controls and $2.5 \%$ of those with a fracture. They found that prostate cancer was associated with a 1.8 fold greater risk of any fracture and a 3.7 fold greater risk of hip fractures. There was no increased risk of vertebral fractures. The increased fracture risk became apparent early after diagnosis and remained pronounced even in long-term survivors. ADT was associated with an odds ratio of 1.7 (1.2-2.5; P <
$0.01)$ and orchidectomy, at $1.7(1.2-2.4 ; \mathrm{P}<0.01)$ added to the overall fracture risk. In all, $3.1 \%$ of hip fractures in this population aged $>50$ years were attributable to prostate cancer (Table 5).

Shahinian studied the records of 50,613 men who were listed in database of the Surveillance, Epidemiology, and End Results program and Medicare as having received a diagnosis of prostate cancer in the period from 1992 through 1997 [36]. The primary outcomes were the occurrence of any fracture and the occurrence of any fracture resulting in hospitalization. Of patients surviving at least five years after diagnosis, 19.4 percent of those who received androgendeprivation therapy had a fracture, as compared with 12.6 percent of those not receiving androgen-deprivation therapy $(\mathrm{P}<0.001)$. The number of patients with fractures requiring hospitalization was $5.2 \%$ in the ADT group vs. $2.4 \%$ in the no ADT group $(\mathrm{P}<0.001)$. In the Cox proportional-hazards analyses, adjusted for characteristics of the patient and the tumor, there was a statistically significant relation between the number of doses of gonadotropin-releasing hormone received during the 12 months after diagnosis and the subsequent risk of fracture (Table 5).

Oefelein assessed the correlation of skeletal fracture with survival in men with prostate cancer on chronic androgen suppressive therapy. 195 consecutive patients on chronic androgen suppression for prostate cancer were evaluated for the history and type of skeletal fracture. Correlation with overall survival was performed via multivariate analysis. 24 patients reported skeletal fracture since the diagnosis of prostate cancer. From the diagnosis of prostate cancer the median survival was 10.1 years in men without history of fractures and 13.3 years in patient with a history of skeletal fracture. $(p=0.04)$. This result suggests that skeletal fracture in patients with prostate cancer is an independent and adverse predictor of survival [37] (Table 5).

There are data that biphosphonates are effective in ADT related osteoporosis in men however, these are small studies

Table 5. Musculoskeletal

\begin{tabular}{|c|c|c|c|}
\hline Author & Population & Treatment & Findings \\
\hline Mittan [34] & 15 prostate cancer. $\mathrm{T} 1-\mathrm{T} 3 \mathrm{~N} 0 \mathrm{M} 0$ & GnRH q 3 months & $\begin{array}{l}\text { Mean bone loss } 3.3 \% \text { in hip } \\
5.3 \% \text { in radius }\end{array}$ \\
\hline Abrahamsen [35] & $\begin{array}{l}15716 \text { men aged }>50 \text { years presenting } \\
\text { with a fracture and } 47149 \\
\text { age-matched control men. } \\
\text { A previous diagnosis of prostate can- } \\
\text { cer had been recorded in } 1.3 \% \text { of con- } \\
\text { trols and } 2.5 \% \text { of those with a fracture. }\end{array}$ & & $\begin{array}{l}\text { Prostate cancer was associated with an increased odds } \\
\text { ratio for all fractures of } 1.8 \text {, for hip fractures of } 3.7 \text {, but no } \\
\text { increased risk of vertebral fractures. } \\
\text { Androgen deprivation therapy (ADT) with an odds } \\
\text { ratio of } 1.7 \text { and orchiectomy, at } 1.7 \text { added to } \\
\text { the overall fracture risk. }\end{array}$ \\
\hline Shahinian [36] & $50613 \mathrm{p}$ with prostate ca. All stages & $\begin{array}{l}31 \% \text { on ADT } \\
\text { (GnRH or orchiectomy) }\end{array}$ & $\begin{array}{l}\text { ADT No ADT } \\
\text { Fracture } 19.4 \% 12.6 \%(\mathrm{P}<0.001) \\
\text { Hospitalization } \\
\text { Due to Fracture } 5.2 \% 2.4 \% \\
(\mathrm{P}<0.001)\end{array}$ \\
\hline Oefelein [37] & $\begin{array}{l}195 \mathrm{p} \text { with prostate cancer } \\
24 \text { patients reported skeletal fracture } \\
\text { since the diagnosis }\end{array}$ & $\begin{array}{l}\text { All on ADT, } 137 \mathrm{GnRH} \\
58 \text { Combined androgen } \\
\text { blockade }\end{array}$ & $\begin{array}{l}\text { Median survival was } 10.1 \text { years in men without } \\
\text { history of fractures and } 13.3 \text { years in patient with a } \\
\text { history of skeletal fracture. }(\mathrm{p}=0.04) \text {. }\end{array}$ \\
\hline
\end{tabular}


and larger ones are needed. In a randomized, double-blind, placebo-controlled, partial crossover trial, 112 men with nonmetastatic prostate cancer receiving ADT were randomized to Alendronate, $70 \mathrm{mg}$ once weekly, or placebo At baseline, $39 \%$ of men had osteoporosis and $52 \%$ had low bone mass. In patients treated with alendronate, bone mineral density increased over 1 year by $3.7 \%(\mathrm{P}<0.001)$ at the spine and $1.6 \%(\mathrm{P}=0.008)$ at the femoral neck. Men in the placebo group had losses of $1.4 \%(\mathrm{P}=0.045)$ at the spine and $0.7 \%(\mathrm{P}=0.081)$ at the femoral neck. At 12 months, the difference between the 2 groups was 5.1 percentage points $(\mathrm{P}<0.001)$ at the spine and was 2.3 percentage points $(\mathrm{P}<0.001)$ at the femoral neck. Bone turnover statistically significantly decreased with active therapy compared with placebo [38].

Michaelson et al. did a 12-month study in which 40 men with nonmetastatic prostate cancer who were receiving a GnRH agonist and had $\mathrm{T}$ scores more than -2.5 were randomly assigned to zoledronic acid (4 mg intravenously on day 1 only) or placebo. BMD of the posteroanterior lumbar spine and proximal femur were measured by dual-energy $\mathrm{x}$ ray absorptiometry. They found that the mean BMD of the posteroanterior lumbar spine decreased by $3.1 \%$ in men assigned to placebo and increased by $4.0 \%$ in men assigned to zoledronic acid $(\mathrm{P}<.001)$. BMD of the total hip decreased by $1.9 \%$ in men assigned to placebo and increased by $0.7 \%$ in men assigned to zoledronic acid $(\mathrm{P}=.004)$. Similar between-group differences were observed for the femoral neck and trochanter. Serum N-telopeptide, a marker of osteoclast activity, decreased significantly after zoledronic acid treatment [39].

ADT also results in estrogen deficiency due to decrease available testosterone to be converted in the peripheral tissues. In a recently completed two-year randomized controlled trial of 1,382 men, toremifene, an oral selective estrogen receptor modulator increased BMD and decreased vertebral fracture incidence in men receiving ADT for prostate cancer [40]. This was the first prospective, placebo controlled trial to assess the risk of fractures in men on ADT. The major entry criteria was advanced prostate cancer on ADT for at least 6 months. Subjects were randomized to receive either $80 \mathrm{mg}$ toremifene citrate daily or matching placebo. In the overall study population, toremifene increase BMD of the hip and lumbar spine by $1.6 \%$ and $2 \%$ after two years compared to placebo. Toremifene demonstrated greater than $50 \%$ reduction in new morphometric vertebral fractures. This drug has been applied for marketing approval in USA.

There is a second large randomized controlled trial that studied the use of Denosumab in the prevention of fractures in patients with prostate cancer on ADT [41].

Denosumab (anti-receptor activator of nuclear factorkappaB ligand antibody) is a novel agent, a fully human monoclonal antibody that inhibits osteoclastic-mediated bone resorption by binding to osteoblast-produced RANKL. By reducing RANKL binding to the osteoclast receptor RANK, bone resorption and turnover decrease.

Men receiving ADT for nonmetastatic PC were randomized to receive subcutaneous denosumab $60 \mathrm{mg}$ every 6 months $(n=734)$ or placebo $(n=734)$, with daily calcium and vitamin D supplements for 3 years. Men $<70$ years old were required to have low BMD or a history of osteoporotic fracture. The primary endpoint was percentage change in lumbar spine BMD at 24 months. Key secondary endpoints were subject incidence of new vertebral fractures and fractures at any site (excluding fractures from severe trauma or pathologic fractures) over 3 years. Denosumab reduced the incidence of new vertebral fractures by $62 \%(\mathrm{p}=0.006)$, fractures at any site by $28 \%(\mathrm{p}=0.10)$, and multiple fractures at any site by $72 \%(\mathrm{p}=0.006)$ over 3 years. In a posthoc analysis, they found a consistent trend showing a positive effect of denosumab on nonvertebral fractures also. The occurrence of any fractures (counting all fractures within a subject) over 3 years was lower with denosumab than placebo $(\mathrm{p}<0.01)$. The subject incidence of fractures at 6 highrisk sites (wrist, humerus, hip, pelvis, leg [excluding patella], and clavicle) was numerically lower with denosumab $(p=0.12)$. Also, fewer subjects in the denosumab arm than in the placebo arm reported fractures at key osteoporotic sites (e.g., 2 for denosumab vs 10 for placebo at the radius).

We recommend using the National Osteoporosis Foundation guidelines that offer concise recommendations regarding prevention, risk assessment, diagnosis and treatment of osteoporosis [42]. You should consider FDA approved medical therapies based on the following: A hip or vertebral fracture, a dual energy x-ray absorptiometry (DXA) measurement of the hip(femoral neck) or spine $\mathrm{T}$-score $<=-2.5$, a low bone mass and US adapted WHO 10 year probability of a hip fracture $>=3 \%$ or 10 -year probability if any major osteroporosis-related fracture $>=20 \%$.

In men with prostate cancer Zoledronic acid has been approved by the FDA only for patient with hormone refractory prostate cancer. Guidelines in how to use Toremifene and Denosumab are needed and these drugs have not been approved yet to use in this setting.

\section{Physical}

ADT induces a lot of physical changes including, gynecomastia, gain weight, increase fat mass, decrease penile size, decrease testicular size and muscle wasting and sarcopenia or loss of lean body mass. Gynecomastia is caused by an increased ratio of estrogen to androgen activity and is worse in patients receiving antiadrogens alone. Gynecomastia can be prevented or decreased if radiation therapy to breast tissue is offered before starting treatment.

ADT increase weight and percentage fat body mass and decrease percentage lean body mass and muscle size in men with non-metastatic prostate cancer. Increased fat resulted primarily from accumulation of subcutaneous rather than intraabdominal adipose tissue [27]. This contrasts with the metabolic syndrome where fat accumulation is mostly intraabdominal.

Percentage fat body mass increased by $9.4 \%(\mathrm{P}<0.001)$, and percentage lean body mass decreased by $2.7 \%$ ( $\mathrm{P}<$ 0.001). Cross-sectional areas of the abdomen and abdominal sc fat increased by $3.9 \%(P=0.003)$ and $11.1 \%(P=0.003)$, respectively. In contrast, the cross-sectional area Crosssectional paraspinal muscle area decreased by $3.2 \%(\mathrm{P}=$ 0.02).

Median weight gain is closed to $6 \mathrm{~kg}$ after one year of ADT [43]. 
Loss of muscle mass in association with decrease hemoglobin can lead to physical weakness and disability.

\section{CONCLUSION}

The use of ADT has dramatically increased in last decade. This therapy is associated with several side effects, the most worrisome being an increase in the risk of diabetes, cardiovascular disease, fractures and possibly, in some cases, an increase in mortality. Needless to say, cardiovascular disease is the most common reason for death among men with prostate cancer, who do not die of prostate cancer.

This information has particular relevance to decisions regarding the use of ADT in men with prostate cancer in settings in which the benefit has not been clearly established. The benefits of ADT treatment should be weighed against these potential risks.

In prostate cancer patients planning to start or already on androgen deprivation therapy we recommend:

- To provide and discuss all these issues, so patients can make a well informed decision.

- To try to modify cardiac risk factors through diet, exercise, or the use of lipid-lowering agents.

- To encourage routine surveillance/control of glucose in patients with or with no previous history of diabetes particularly when their BMI is increase with appropriate preventive and treatment measures.

- To monitor bone mineral density and start bisphosphanate treatment if osteoporosis develops or a fracture occur.

\section{REFERENCES}

[1] Satariano WA, Ragland KE, Van Den Eeden SK. Cause of death in men diagnosed with prostate carcinoma. Cancer 1998; 83(6): 11808.

[2] Lu-Yao G, Stukel TA, Yao SL. Changing patterns in competing causes of death in men with prostate cancer: a population based study. J Urol 2004; 171(6 Pt 1): 2285-90.

[3] Loblaw DA, Virgo KS, Nam R, et al. Initial hormonal management of androgen-sensitive metastatic, recurrent, or progressive prostate cancer: 2006 update of an American Society of Clinical Oncology practice guideline. J Clin Oncol 2007; 25(12): 1596-605.

[4] Barry MJ, Delorenzo MA, Walker-Corkery ES, Lucas FL, Wennberg DC. The rising prevalence of androgen deprivation among older American men since the advent of prostate-specific antigen testing: a population-based cohort study. BJU Int 2006; 98(5): 973-8.

[5] Walsh B, Schiff, I. Vasomotor flushes. Ann NY Acad Sci 1990; 592: 346-56; discussion 390-4.

[6] Kouriefs C, Georgiou M, Ravi R. Hot flushes and prostate cancer: pathogenesis and treatment. BJU Int 2002; 89(4): 379-83.

[7] Spetz AC, Hammar M, Pettersson W, Varenhorst E. Hot flushes and prostate cancer: pathogenesis and treatment. BJU Int 2002; 90(4): 476; author reply 476-7.

[8] Voegeli TA, Kurtz A, Grimm MO, Effert P, Eckardt KU. Anemia under androgen deprivation: influence of flutamide, cyproteroneacetate and orchiectomy on the erythropoietin system. Horm Metab Res 2005; 37(2): 89-93.

[9] Strum SB, McDermed JE, Scholz MC, Johnson H, Tisman G. Anaemia associated with androgen deprivation in patients with prostate cancer receiving combined hormone blockade. Br J Urol 1997; 79(6): 933-41.

[10] Qian LX, Hua LX, Wu HF, et al. Anemia in patients on combined androgen block therapy for prostate cancer. Asian J Androl 2004; 6(4): $383-4$.
[11] Gurbuz N, Mammadov E, Usta MF. Hypogonadism and erectile dysfunction: an overview. Asian J Androl 2008; 10(1): 36-43.

[12] Pasquali R, Casimirri F, Cantobelli S, et al. Effect of obesity and body fat distribution on sex hormones and insulin in men. Metabolism 1991; 40(1): 101-4.

[13] Francavilla MB, Pelliccione F, Necozione S, Francavilla F. Vascular aetiology of erectile dysfunction. Int J Androl 2005; 28(s2): 359.

[14] Selvin E, Burnett AL, Platz EA. Prevalence and risk factors for erectile dysfunction in the US. Am J Med 2007; 120(2): 151-7.

[15] Christopher J, DiBlasio JBM, Ithaar H, et al. Patterns of sexual and erectile dysfunction and response to treatment in patients receiving androgen deprivation therapy for prostate cancer. BJU Int 2008; 102(1): 39-43.

[16] Salminen EK, Portin RI, Koskinen A, Helenius H, Nurmi M. Associations between serum testosterone fall and cognitive function in prostate cancer patients. Clin Cancer Res 2004; 10(22): 7575-82.

[17] Jenkins VA, Bloomfield DJ, Shilling VM, Edginton TL. Does neoadjuvant hormone therapy for early prostate cancer affect $\operatorname{cog}$ nition? Results from a pilot study. BJU Int 2005; 96(1): 48-53.

[18] Green HJ, Pakenham KI, Headley BC, et al. Altered cognitive function in men treated for prostate cancer with luteinizing hormone-releasing hormone analogs and cyproterone acetate: a randomized controlled trial. BJU Int 2002; 90(4): 427-32.

[19] Mohile SG, Mustian K, Bylow K, Hall W, Dale W. Management of complications of androgen deprivation therapy in the older man. Crit Rev Oncol Hematol 2009; 70(3): 235-55

[20] Pirl WF, Siegel GI, Goode MJ, Smith MR. Depression in men receiving androgen deprivation therapy for prostate cancer: a pilot study. Psychooncology 2002; 11(6): 518-23.

[21] Pirl WF, Greer JA, Goode M, Smith MR. Prospective study of depression and fatigue in men with advanced prostate cance receiving hormone therapy. Psychooncology 2008; 17(2): 148-53.

[22] Smith MR, Lee H, Nathan DM. Insulin sensitivity during combined androgen blockade for prostate cancer. J Clin Endocrinol Metab 2006; 91(4): 1305-8.

[23] Basaria S, Muller DC, Carducci MA, Egan J, Dobs AS. Hyperglycemia and insulin resistance in men with prostate carcinoma who receive androgen-deprivation therapy. Cancer 2006; 106(3): 581-8.

[24] Derweesh IH, Diblasio CJ, Kincade MC, et al. Risk of new-onset diabetes mellitus and worsening glycaemic variables for established diabetes in men undergoing androgen-deprivation therapy for prostate cancer. BJU Int 2007; 100(5): 1060-5.

[25] No authors listed. Executive Summary of the Third Report of the National Cholesterol Education Program (NCEP) Expert Panel on Detection, Evaluation, and Treatment of High Blood Cholesterol in Adults (Adult Treatment Panel III). JAMA 2001; 285(19): 248697.

[26] Braga-Basaria M, Dobs AS, Muller DC, et al. Metabolic Syndrome in Men With Prostate Cancer Undergoing Long-Term AndrogenDeprivation Therapy. J Clin Oncol 2006; 24(24): 3979-83.

[27] Smith MR, Finkelstein JS, McGovern FJ, et al. Changes in body composition during androgen deprivation therapy for prostate cancer. J Clin Endocrinol Metab 2002; 87(2): 599-603.

[28] No authors listed. Third report of the National Cholesterol Education Program (NCEP) expert panel on detection, evaluation, and treatment of high blood cholesterol in adults (Adult Treatment Panel iii): final report. Circulation 2002; 106(25): 3143-421.

[29] Keating NL, O'Malley AJ, Smith, MR. Diabetes and cardiovascular disease during androgen deprivation therapy for prostate cancer. J Clin Oncol 2006; 24(27): 4448-56.

[30] Tsai HK, D'Amico AV, Sadetsky N, Chen MH, Carroll PR. Androgen deprivation therapy for localized prostate cancer and the risk of cardiovascular mortality. J Natl Cancer Inst 2007; 99(20): 1516-24.

[31] Saigal CS, Gore JL, Krupski TL, et al. Androgen deprivation therapy increases cardiovascular morbidity in men with prostate cancer. Cancer 2007; 110(7): 1493-500.

[32] Hayes J. Short-course androgen suppression therapy prior to brachytherapy for favorable risk prostate cancer and the risk of all cause mortality in men with or without preexisting cardiovascular disease. J Clin Oncol 2009; 27(15s): Abst 5066.

[33] Liu H, Paige NM, Goldzweig CL, et al. Screening for osteoporosis in men: a systematic review for an American College of Physicians guideline. Ann Intern Med 2008; 148(9): 685-701. 
[34]. Mittan D, Lee S, Miller E, et al. Bone loss following hypogonadism in men with prostate cancer treated with GnRH analogs. J Clin Endocrinol Metab 2002; 87(8): 3656-61.

[35] Abrahamsen B, Nielsen MF, Eskildsen P, et al. Fracture risk in Danish men with prostate cancer: a nationwide register study. BJU Int 2007; 100(4): 749-54.

[36] Shahinian VB, Kuo YF, Freeman JL, Goodwin JS. Risk of fracture after androgen deprivation for prostate cancer. N Engl J Med 2005; 352(2): 154-64.

[37] Oefelein MG, Ricchiuti V, Conrad W, Resnick MI. Skeletal fractures negatively correlate with overall survival in men with prostate cancer. J Urol 2002; 168(3): 1005-7.

[38] Greenspan SL, Nelson JB, Trump DL, Resnick NM. Effect of once-weekly oral alendronate on bone loss in men receiving androgen deprivation therapy for prostate cancer: a randomized trial. Ann Intern Med 2007; 146(6): 416-24.
[39] Michaelson MD, Kaufman DS, Lee H, et al. Randomized controlled trial of annual zoledronic acid to prevent gonadotropinreleasing hormone agonist-induced bone loss in men with prostate cancer. J Clin Oncol 2007; 25(9): 1038-42.

[40] Veverka KA. The effect of toremifene citrate on BMD in men on ADT: A phase III clinical trial. J Clin Oncol 2009; 27(15s): Abst 5055 .

[41] Saad F. Denosumab for prevention of fractures in men receiving androgen deprivation therapy for prostate cancer. J Clin Oncol 2009; 27(15s): Abst 5056.

[42] National Osteoporosis Foundation. [Accessed on October 29, 2009] Available from: www.nof.org

[43] Smith MR. Osteoporosis and obesity in men receiving hormone therapy for prostate cancer. J Urol 2004; $172(5$ Pt 2): S52-6; discussion S56-7.

(C) Gustavo Fernandez-Castro; Licensee Bentham Open.

This is an open access article licensed under the terms of the Creative Commons Attribution Non-Commercial License (http://creativecommons.org/licenses/ by-nc/3.0/) which permits unrestricted, non-commercial use, distribution and reproduction in any medium, provided the work is properly cited. 